\title{
Trichoderma aureoviride: phylogenetic position and characterization
}

\author{
Elke LIECKFELDT ${ }^{1}$, Cornelia M. KULLNIG ${ }^{2}$, Christian P. KUBICEK ${ }^{2}$, Gary J. SAMUELS ${ }^{3 *}$ and Thomas BÖRNER ${ }^{1}$ \\ ${ }^{1}$ Humboldt-Universität zu Berlin, Institut für Biologie (Genetik), Chausseestr. 117, D-10115 Berlin, Germany. \\ ${ }^{2}$ Technische Universität Wien, Institut für Biochemische Technologie und Mikrobiologie, Getreidemarkt 9/172-5, A-1060 Wien, Austria. \\ ${ }^{3}$ United States Department of Agriculture, Agricultural Research Service, Systematic Botany and Mycology Laboratory, Room 304, B-011A, \\ BARC-West, Beltsville, MD 20705-2350, USA. \\ E-mail:garys@int.ars-grin.gov \\ Received 29 November 1999; accepted 5 August 2000.
}

\begin{abstract}
The identity of strains identified as Trichoderma aureoviride/Hypocrea aureoviridis was reconsidered. Trichoderma aureoviride was isolated originally from a specimen identified as $H$. aureoviridis and thus is $H$. aureoviridis. The morphological and molecular characters of most strains identified as $T$. aureoviride differ from those of the ex-type but are more typical of $T$. harzianum, a member of sect. Pachybasium. Molecular data do not support inclusion of T. aureoviride in sect. Trichoderma, nor was there strong phenotypic similarity between $H$. aureoviridis and $H$. rufa. In the ITS phylogeny the T. aureoviride ex-type and other collections of $H$. aureoviridis form a strongly supported clade that is separate from any other recognized section of Trichoderma. Hypocrea vinosa, which was originally included in the T. aureoviride aggregate species concept, is distinct from T. aureoviride, but closely allied with $H$. rufa/T. viride. Trichoderma aureoviride/H. aureoviridis is a rare species, restricted to the UK and the Netherlands. We redefine T. aureoviride, limiting it to strains with very slow growth rate, effuse conidiation, and the ITS-I and 2 sequence type D.
\end{abstract}

\section{INTRODUCTION}

Trichoderma aureoviride (Rifai 1969) is often cited for its ability to produce enzymes (Kubicek 1982, Bruce et al. 1995), have biocontrol potential (Bruce et al. 1996, Cutler et al. 1999), or plant growth enhancing activities (Calvet et al. 1993, Camprubi et al. 1995). The name T. aureoviride was originally used for an aggregate species, but was based on single ascospore isolates from a collection identified as Hypocrea aureoviridis (ascomycetes, Hypocreales, Phillips \& Plowright 1880; Rifai \& Webster 1966), a species originally described from material collected on hardwood in the UK. Rifai (1969) also included the anamorph of $H$. vinosa in the $T$. aureoviride species aggregate on the basis of a perceived similarity in conidiophore branching.

The T. aureoviride aggr. was one of the nine aggregate species of Trichoderma Rifai (1969) recognized. While Rifai considered each of the aggregate species to include more than one morphologically cryptic species, Bissett (1991a) divided Trichoderma into five sections and included T. aureoviride in sect. Trichoderma along with the type species of the genus, $T$. viride, and other species. Gams \& Bissett (1998) accepted this taxonomy. Here we examine aspects of the identity and phylogenetic placement of $H$. aureoviridis/T. aureoviride.

Although correct identification is essential to the com-

* Corresponding author. munication of research results, Trichoderma remains taxonomically difficult. This is true, in part, because cultures present few quantifiable morphological characters that, themselves, are continuous. Additional characters useful for the taxonomy of Trichoderma have been obtained from DNA (see Lieckfeldt, Kuhls \& Muthumeenakshi 1998a). Using DNA sequence analysis we found some species of Trichoderma reported to have specific biological properties were frequently misidentified when only morphology was considered (Kuhls, Lieckfeldt \& Börner 1995, Lieckfeldt et al. 1999). Because of the frequency of misidentification of other species, we questioned whether reported strains of $T$. aureoviride also had been incorrectly identified.

We also questioned the relationship between $H$. rufa and $H$. aureoviridis implied by including their anamorphs in the same section of Trichoderma for three reasons. First, the teleomorph of $T$. aureoviride, H. aureoviridis, is anatomically and morphologically easily distinguished from $H$. rufa, the teleomorph of T. viride (Rifai \& Webster 1966, Samuels, pers. obs.) to the extent that one would not predict a close relationship between the two. Doi (1972) included H. rufa and H. aureoviridis f. macrospora in different subsections of sect. Hypocrea. Second, there is little morphological similarity between $T$. aureoviride and T. viride (compare Webster 1964 with Rifai \& Webster 1966, Samuels, pers. obs.; see also Samuels, Lieckfeldt \& Nirenberg 1999 for a redescription of T. viride). Further, preliminary DNA-analysis (ITS-1- and ITS-2 sequencing) 
Table 1. List of strains of the Hypocrea aureoviridis/Trichoderma aureoviride complex including information about growth, grouping according to molecular data, and ITS GenBank accession number.

\begin{tabular}{|c|c|c|c|c|c|c|}
\hline Species & Strain ${ }^{*}$ & $\begin{array}{l}\text { Species (as } \\
\text { reidentified) }\end{array}$ & $\begin{array}{l}\text { Literature } \\
\text { source }\end{array}$ & $\begin{array}{l}\text { Geographic } \\
\text { origin }\end{array}$ & $\begin{array}{l}\text { Groups from } \\
\text { molecular } \\
\text { datat }\end{array}$ & $\begin{array}{l}\text { ITS } \\
\text { GenBank } \\
\text { accession no. }\end{array}$ \\
\hline $\begin{array}{l}\text { H. aureoviridis } \\
\text { (ex-type strain of } \\
\text { T. aureoviride) }\end{array}$ & $\begin{array}{l}\text { CBS } 245.63 \\
=\text { SHD-M } 2663 \\
\text { (Rifai) }\end{array}$ & H. aureoviridis & $\begin{array}{l}\text { Rifai (1969); } \\
\text { CBS catalogue }\end{array}$ & $\begin{array}{l}\text { UK } \\
\text { Corylus } \\
\text { avellana }\end{array}$ & $\mathrm{D}$ & Z48819 \\
\hline H. aureoviridis & CBS 525.63 & H. aureoviridis & $\begin{array}{l}\text { Rifai \& Webster, (1966); } \\
\text { CBS catalogue }\end{array}$ & $\begin{array}{l}\text { UK } \\
\text { Sambucus } \\
\text { nigra }\end{array}$ & $\mathrm{D}$ & AF191040 \\
\hline H. aureoviridis & CBS 103.69 & H. aureoviridis & $\begin{array}{l}\text { Bramley } \\
\text { 1030, CBS }\end{array}$ & $\begin{array}{l}\text { UK } \\
\text { Acer } \\
\text { campestre }\end{array}$ & $\mathrm{D}$ & AF194004 \\
\hline H. aureoviridis & IMI 138258 & H. aureoviridis & $\begin{array}{l}\text { Bramley } \\
\text { 1030, CABI catalogue }\end{array}$ & $\begin{array}{l}\text { UK } \\
\text { Acer } \\
\text { campestre }\end{array}$ & $\mathrm{D}$ & AF19021 \\
\hline H. aureoviridis & CBS 138.79 & H. aureoviridis & $\begin{array}{l}\text { CBS } \\
\text { catalogue }\end{array}$ & $\begin{array}{l}\text { NL } \\
\text { decaying } \\
\text { wood }\end{array}$ & $\mathrm{D}$ & AF194005 \\
\hline H. aureoviridis & CBS 628.77 & $\begin{array}{l}\text { T. cfr } \\
\text { harzianum }\end{array}$ & $\begin{array}{l}\text { van Schothorst, } \\
\text { CBS }\end{array}$ & $\begin{array}{l}\mathrm{NL} \\
\text { foodstuff }\end{array}$ & B & AF194006 \\
\hline H. aureoviridis & IMI 355906 & H. aureoviridis & CABI catalogue & $\begin{array}{l}\text { UK } \\
\text { Fagus } \\
\text { sylvatica }\end{array}$ & $\mathrm{D}$ & AF194016 \\
\hline H. aureoviridis & IMI 311745 & H. aureoviridis & CABI catalogue & $\begin{array}{l}\text { UK } \\
\text { decorticated } \\
\text { wood }\end{array}$ & $\mathrm{D}$ & AF194018 \\
\hline H. aureoviridis & $\begin{array}{l}\text { DAOM } \\
172826 \mathrm{~A}\end{array}$ & Hypocrea sp. & Bissett (1991) & $\begin{array}{l}\text { Canada } \\
\text { rotting log, } \\
\text { isolated from } \\
\text { ascospores }\end{array}$ & E & AJ230662 \\
\hline H. aureoviridis & $\begin{array}{l}\text { DAOM } \\
172826 \mathrm{~B}\end{array}$ & Hypocrea sp. & Bissett (1991) & $\begin{array}{l}\text { Canada } \\
\text { rotting log, } \\
\text { isolated from } \\
\text { stroma tissue }\end{array}$ & E & AJ230662 \\
\hline T. aureoviride & $\begin{array}{l}\text { DAOM } \\
175924\end{array}$ & $\begin{array}{l}\text { T. cfr } \\
\text { harzianum }\end{array}$ & DAOM catalogue & $\begin{array}{l}\text { Canada, } \\
\text { on rotted } \\
\text { stump of } \\
\text { Acer sp. }\end{array}$ & B & AF191039 \\
\hline T. aureoviride & IMI 091968 & T. citrinoviride & CABI catalogue & $\begin{array}{l}\text { UK } \\
\text { Fagus } \\
\text { sylvatica }\end{array}$ & C & AF194017 \\
\hline T. aureoviride & IMI 113135 & T. harzianum & $\begin{array}{l}\text { produces } \\
\text { penicillin-amidase; } \\
\text { CABI catalogue }\end{array}$ & $\begin{array}{l}\text { UK } \\
\text { air }\end{array}$ & B & AF194019 \\
\hline T. aureoviride & IMI 112086 & T. harzianum & CABI catalogue & Egypt soil & B & AF194020 \\
\hline T. aureoviride & BBA 65638 & $\begin{array}{l}\text { T. cfr } \\
\text { harzianum }\end{array}$ & H. Nirenberg & $\begin{array}{l}\text { Czech } \\
\text { Republic } \\
\text { cellulose } \\
\text { producing }\end{array}$ & B & AF194007 \\
\hline H. vinosa & $\begin{array}{l}\text { CBS } 247.63 \\
=\text { DAOM } \\
167638\end{array}$ & H. vinosa & $\begin{array}{l}\text { Rifai \& Webster } \\
\text { (1966) }\end{array}$ & $\mathrm{NZ}$ & A2 & AF191041 \\
\hline H. vinosa & $\begin{array}{l}\text { CBS } 960.68 \\
=\text { DAOM } 167642\end{array}$ & H. vinosa & $\begin{array}{l}\text { Rifai \& Webster } \\
\text { (1966) }\end{array}$ & $\begin{array}{l}\text { USA, OH } \\
\text { sand }\end{array}$ & B & AF1910038 \\
\hline T. harzianum $\neq$ & NR 5546 & T. harzianum & $\begin{array}{l}\text { Fujimori \& } \\
\text { Okuda (1994) }\end{array}$ & $\begin{array}{l}\text { Japan, } \\
\text { Kanagawa } \\
\text { soil }\end{array}$ & B & AF194008 \\
\hline T. harzianum $\neq$ & NR 5555 & T. harzianum & $\begin{array}{l}\text { Fujimori \& } \\
\text { Okuda (1994) }\end{array}$ & $\begin{array}{l}\text { Japan, } \\
\text { Tokyo soil }\end{array}$ & B & AF194009 \\
\hline
\end{tabular}


Table 1. (cont.)

\begin{tabular}{|c|c|c|c|c|c|c|}
\hline Species & Strain* & $\begin{array}{l}\text { Species (as } \\
\text { reidentified) }\end{array}$ & $\begin{array}{l}\text { Literature } \\
\text { source }\end{array}$ & $\begin{array}{l}\text { Geographic } \\
\text { origin }\end{array}$ & $\begin{array}{l}\text { Groups from } \\
\text { molecular } \\
\text { datat }\end{array}$ & $\begin{array}{l}\text { ITS } \\
\text { GenBank } \\
\text { accession no. }\end{array}$ \\
\hline T. aureoviride & NR 6883 & T. harzianum & $\begin{array}{l}\text { Fujimori \& } \\
\text { Okuda (1994) }\end{array}$ & $\begin{array}{l}\text { Japan, } \\
\text { Kanagawa } \\
\text { soil }\end{array}$ & B & AF194010 \\
\hline T. harzianum $\neq$ & NR 6929 & T. harzianum & $\begin{array}{l}\text { Fujimori \& } \\
\text { Okuda (1994) }\end{array}$ & $\begin{array}{l}\text { Japan, } \\
\text { Chiba soil }\end{array}$ & B & AF194011 \\
\hline T. aureoviride & NR 6931 & $\begin{array}{l}\text { T. cfr } \\
\text { inhamatum }\end{array}$ & $\begin{array}{l}\text { Fujimori \& } \\
\text { Okuda (1994) }\end{array}$ & $\begin{array}{l}\text { Japan, } \\
\text { Chiba } \\
\text { soil }\end{array}$ & B & AF194012 \\
\hline T. aureoviride & NR 6938 & T. harzianum & $\begin{array}{l}\text { Fujimori \& } \\
\text { Okuda (1994) }\end{array}$ & $\begin{array}{l}\text { Japan, } \\
\text { Okinawa } \\
\text { soil }\end{array}$ & B & AF194013 \\
\hline T. aureoviride & NR 6940 & T. harzianum & $\begin{array}{l}\text { Fujimori \& } \\
\text { Okuda (1994) }\end{array}$ & $\begin{array}{l}\text { Japan, } \\
\text { Okinawa } \\
\text { soil }\end{array}$ & B & AF194014 \\
\hline T. aureoviride & NR 6950 & T. harzianum & $\begin{array}{l}\text { Fujimori \& } \\
\text { Okuda (1994) }\end{array}$ & $\begin{array}{l}\text { Japan, } \\
\text { Okinawa } \\
\text { soil }\end{array}$ & B & AF194015 \\
\hline
\end{tabular}

* ATCC, American Type Culture Collection, Manasas, VA; BBA, Biologische Bundesanstalt, Berlin; CBS, Centraalbureau voor Schimmelcultures, Utrecht; DAOM, Agriculture \& Agri-Food Canada Research Branch, Eastern Cereal \& Oilseed Research Centre, Ottawa; IMI, CABI Bioscience, Egham, UK; NR, Nippon Roche.

+ Molecular data considered: ITS- 1 + ITS-2 sequences, RFLP patterns of $28 \mathrm{~S}$ rDNA with MspI and HhaI, and RAPD patterns produced by using primers $(\mathrm{GTG})_{5},(\mathrm{GACA})_{4}, \mathrm{M} 13$ and ROB; Groupings A1, A2, B and C refer to Kindermann et al. (1998); D introduced here stands for 'true' H. aureoviridis.

\# Strains reported as T. aureoviride in Fujimori \& Okuda (1994), but when provided reidentified as T. harzianum.

revealed that the ex-type culture of $T$. aureoviride was strikingly different from ex-type cultures of all other Trichoderma species (Kuhls et al. 1997, Kindermann et al. 1998).

Here we discuss results from RFLP analysis of the $28 \mathrm{~S}$ rRNA gene sequencing of the ITS-I-ITS-2 rDNA spacer region, and RAPD analysis of most available isolates identified as $H$. aureoviridis or $T$. aureoviride and $H$. vinosa. The results show that the morphological and molecular characters of the majority of the T.aureoviride strains are not in accordance with those of the ex-type strain. Molecular and morphological characters also readily distinguish between $H$. aureoviridis and T. aureoviride and show them not to be closely related. Finally we present phenotypic characters that aid in identification of T. aureoviride.

\section{MATERIALS AND METHODS}

\section{Fungal cultures}

Cultures identified as Hypocrea aureoviridis/Trichoderma aureoviride and $H$. vinosa were obtained from researchers and from public culture collections (Table 1). They were cultured and grown for DNA isolation as described by Kuhls et al. (1995).

\section{DNA procedures}

DNA isolation, PCR amplification of rDNA fragments, PCR fingerprinting, RFLP analysis of $28 \mathrm{~S} \mathrm{rDNA}$, and DNA sequencing of internal transcribed spacer regions from the PCR amplified rDNA fragments were performed as described by Lieckfeldt et al. (1998b) and Kindermann et al. (1998).

\section{Phylogenetic analysis}

Sequences were automatically aligned using the program CLUSTAL W, and finally optimized visually. The aligned data set is deposited in TreeBase (SN536). The actual sequences have been deposited at GenBank (Table 1). Sequences for the two species of the outgroup taxon, Hypomyces, were from GenBank (Y17088, Y17093). Phylogenetic trees were constructed using the parsimony options of PAUP, version 4.0 beta (Swofford 1998). The most parsimonious trees were generated with the heuristic search algorithm and the following conditions: TBR branch swapping, closest sequence addition, branch collapsing option. Single gaps were treated as a fifth base. Gaps of more than three bp were handled as missing data, and an additional set of characters was added to the data matrix to signify the presence or absence of particular gaps which convey important phylogenetic information that would have been lost otherwise. The additional set of characters was defined by using a 1/0-matrix with $1=$ gap and $0=$ nucleotides. The matrix contains $10 \mathrm{1} / 0$-characters which refer to the following parts of the $701 \mathrm{nt}$ long sequence of the ITS-1-5.8S-ITS-2 sequence considered in the analysis. ITS-1: nt 113-118 (matrix character 1), 166-170 (2), 191-203 (3), 204-210 (4), 246-250 (5), 256-261 (6), 261-270 (7), 270-276 (8). ITS-2: nt 502-511 (9), 512-517 (10). Bootstrap values were calculated from 1000 replications. 


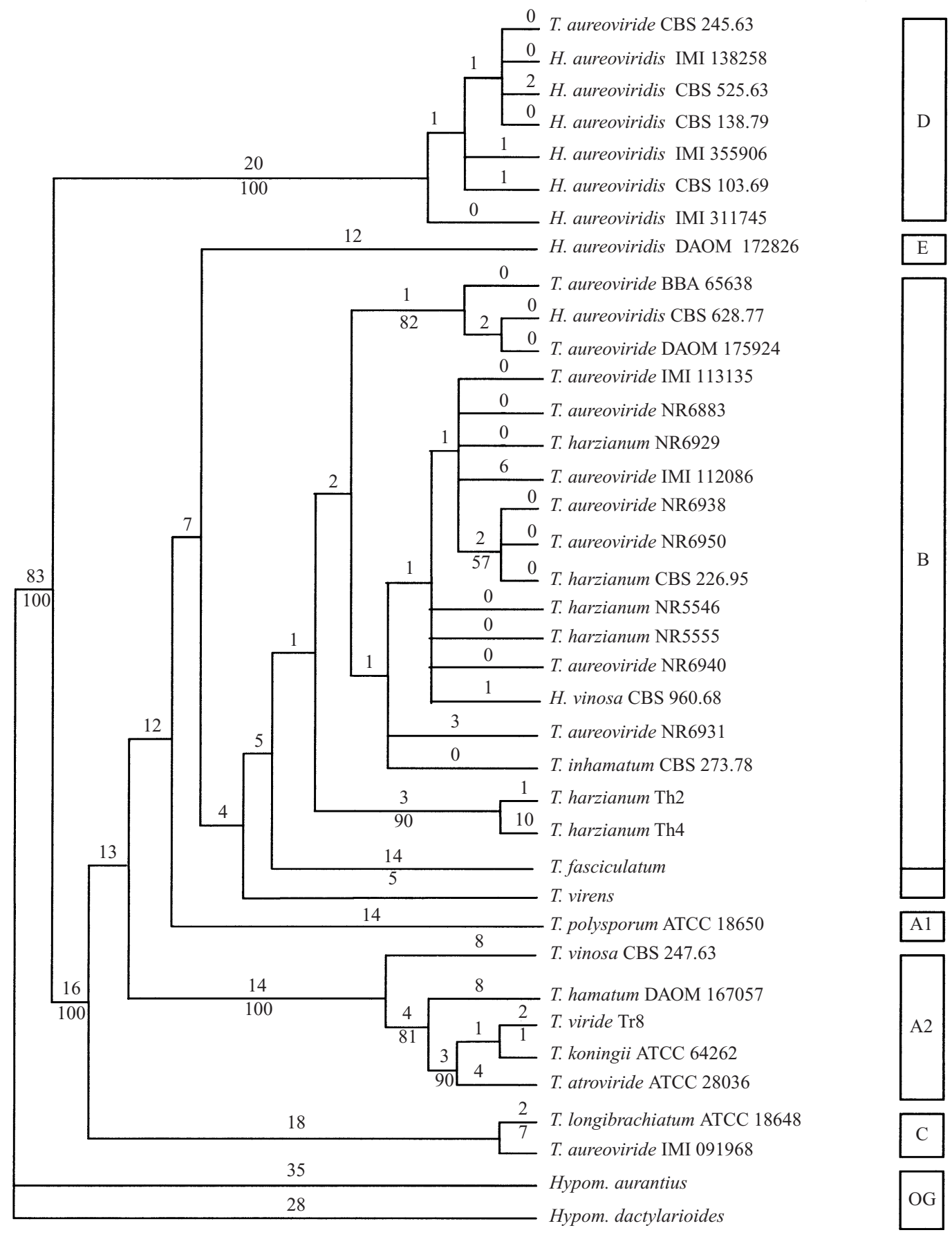

Fig. 1. Phylogenetic position of Trichoderma aureoviride/Hypocrea aureoviridis in Trichoderma. The cladogram is one of the two most parsimonious trees obtained by analysis of sequence data from the total ITS-1-5. 8S-ITS-2 rDNA region. Hypomyces aurantius and H. dactyarioides were used as outgroup. Trees are the results of a PAUP $4.02 \mathrm{~b}$ analysis using the heuristic search option $(381$ steps, $\mathrm{CI}=$ $0.743, \mathrm{HI}=0257, \mathrm{RI}=0.869$ ). The bootstrap support from 1000 replications is indicated below the branches; branches without values occurred in less than $50 \%$ of the bootstrapped trees. Numbers above the branches give the nucleotide differences. A1, A2, B, and C refer to main clades in Trichoderma ITS phylogeny as defined by Kindermann et al. (1998); letters D and E describe new clades for 'true' T. aureoviride and Hypocrea sp. (DAOM 172826), respectively.

\section{Morphology}

Colony characters and the characteristics of conidiophores and conidia were taken from cultures grown on cornmeal dextrose agar (CMD: Difco cornmeal agar $+2 \%$ glucose), malt extract agar (MEA, Difco), potato dextrose agar (PDA,
Difco), and special nutrient agar (SNA, Nirenberg 1976). The colour standard was Kornerup \& Wanscher (1978). To obtain growth rates and colony characters, cultures were first inoculated onto freshly prepared CMD in Petri dishes. When the colonies were visibly growing at $20-21^{\circ} \mathrm{C}$, within $1 \mathrm{wk}$, a $5 \mathrm{~mm}$ diam plug of the culture was taken from the actively 
growing edge and inoculated onto a freshly made $9 \mathrm{~cm}$ diam Petri dish containing $20 \mathrm{ml}$ PDA or MEA. Morphological characters of conidiophores and conidia were obtained from cultures grown on MEA or CMD at $20^{\circ}$, alternating $12 \mathrm{~h}$ dark and $12 \mathrm{~h}$ cool white fluorescent light. Where possible, 30 individuals of each morphological parameter were measured. All conidiophores and conidia were first hydrated in $3 \% \mathrm{KOH}$ and the measurements immediately made directly from $\mathrm{KOH}$; as the $\mathrm{KOH}$ evaporated it was replaced by water from which additional measurements and all images were taken. There was no apparent difference between measurements made in $\mathrm{KOH}$ and in water.

Specimens of the $H$. aureoviridis collections from which some of the cultures were derived were obtained from the Centraalbureau voor Schimmelcultures (CBS), The University of Sheffield (SHD), and CABI Bioscience (IMI). Stromata were rehydrated in $3 \% \mathrm{KOH}$. Where possible, stromata with perithecia were sectioned following the protocol of Samuels et al. (1998) and 30 each part ascospores and asci were measured from water.

\section{RESULTS}

\section{Molecular data}

\section{ITS sequence analysis}

The total length of the rDNA fragments amplified from the 24 strains listed in Table 1 by using the primers SR6R, 5.8SR, 5.8S, and LRI (Vilgalys \& Hester 1990) varied from 621 base pairs for Hypocrea vinosa (CBS 247.63) to $672 \mathrm{bp}$ in Trichoderma aureoviride (ex-type CBS 245.63). Length differences of ITS in Trichoderma species belonging to different sections of the genus, a result of considerable indels in the ITS-1, were described earlier (Kuhls et al. 1997). With its 230 bp, the ITS-1 of the T. aureoviride ex-type strain (CBS 245.63) is longer than that of any other Trichoderma isolates examined. In contrast, lengths of ITS-2 varied only slightly (168-182 bp). The calculated G + C content of ITS-1 ranged from 54 to $60 \%$ in all species, except for the T. aureoviride ex-type (65\%). The $\mathrm{G}+\mathrm{C}$ content of ITS-2 was higher than that of ITS-1 (about $65 \%$ ), and displayed slightly higher values (68\%) for species in sect. Longibrachiatum and for the ex-type strain of T. aureoviride.

For phylogenetic analysis of sequence data, a 692-bp

Table 2. Sequence variation in ITS- 1 and ITS- 2 in the Trichoderma aureoviride ex-type strain and related Hypocrea aureoviridis strains. Base pairs indicate positions based on the whole $689 \mathrm{bp}$ fragment which was used for the PAUP analysis.

\begin{tabular}{|c|c|c|}
\hline Species/strain & $\begin{array}{l}\text { ITS-1 } \\
\text { (bp position 185-194) }\end{array}$ & $\begin{array}{l}\text { ITS-2 } \\
\text { (bp position 434) }\end{array}$ \\
\hline T. aureoviride CBS 245.63 & C C T T T T C C C C & $\mathrm{T}$ \\
\hline H. aureoviridis CBS 525.63 & С С T T T Т С С С & $\mathrm{T}$ \\
\hline H. aureoviridis IMI 138258 & C C T T T T C C C C & $\mathrm{T}$ \\
\hline H. aureoviridis CBS 138.79 & C C T T T T T C C C & $\mathrm{T}$ \\
\hline $\begin{array}{l}\text { H. aureoviridis CBS } 103.69 \\
\text { (= IMI 138258) }\end{array}$ & C C C T T T C C C & C \\
\hline H. aureoviridis IMI 355906 & C C C T T T C C C & $\mathrm{T}$ \\
\hline H. aureoviridis IMI 311745 & C C C T T T T C C & $\mathrm{T}$ \\
\hline
\end{tabular}

fragment (including gaps from alignment) comprising total ITS-1, 5.8 S rDNA and ITS-2 sequences of 38 taxa, including the 25 putative $T$. aureoviride and $H$. vinosa isolates, was used. Parsimony analysis was performed, using Hypomyces aurantius and $H$. dactylarioides as outgroup taxa, and the two most parsimonious trees were obtained. The T. aureoviride ex-type strain and six other $H$. aureoviridis isolates form a basal clade to all other species of Trichoderma (Fig. 1, clade D). The seven strains of clade D are only slightly variable in their ITS sequences. Surprisingly, there is a sequence difference in ITS$I$ as well as in ITS-2 between two cultures of a single strain of $H$. aureoviridis (i.e. CBS 103.69 and IMI 138258). Repeated sequencing of new DNA fragments gave the same result. The respective sequence patterns of CBS 103.69 and IMI 138258 are compared to the other $H$. aureoviridis strains of that group (Table 2). All other isolates identified as T. aureoviride clustered within or in the vicinity of previously identified clades (Kuhls et al. 1996, Kindermann et al. 1998). One isolate (IMI 091968) clustered with the T. longibrachiatum ex-type culture (ATCC 18648) and exhibited ITSI and two sequences identical to $T$. citrinoviride. The eight T. aureoviride strains of Fujimori \& Okuda (1994) formed a clade together with T. harzianum and T. inhamatum (in the main clade B as described in Kindermann et al. 1998). No evidence for a close relationship of $T$. aureoviride to $H$. vinosa was obtained, as one isolate of the latter species (CBS 247.63) clustered with species from sect. Trichoderma, whereas the other (CBS 960.68) clustered in the clade containing $T$. harzianum/T. inhamatum. The remaining strains identified as $T$. aureoviride yielded unique sequence characteristics and potentially constitute new species. Three of them, DAOM 175924, BBA 65638 and $H$. aureoviridis CBS 628.77, exhibited only two bp difference to each other, and formed a well-supported cluster with a basal position to the $T$. harzianum/T. inhamatum clade. Another isolate, DAOM 172826 (A/B), occupied a position basal to clade B; exhibiting a sequence significantly different from all other strains investigated. It is defined as clade $\mathrm{E}$ here. The clades containing T. polysporum and the species from sect. Trichoderma (previously termed A1 and A2; Kindermann et al. 1998), and another clade representing sect. Longibrachiatum (C in Fig. 1), are well resolved in the tree.

\section{RFLP analysis of $28 S$ rDNA}

Strains identified above as corresponding to the T. aureoviride ex-type strain were also distinguished by a clearly different RFLP pattern with the restriction enzymes HhaI and MspI. Furthermore, overall 28S-rDNA RFLP patterns were consistent with the grouping established by ITSI- and ITS-2-based parsimony analysis (data not shown)

\section{PCR fingerprinting}

PCR fingerprinting was performed with the telomere primers $(\mathrm{GACA})_{4}$ and (GTG) $)_{5}$, the bacteriophage M13 core sequence, and the decamer primer ROB (Lieckfeldt et al. 1998a). All four primers yielded highly similar fragment patterns with six strains of the T. aureoviride ex-type clade, which were clearly 
different from the other strains (Fig. 2A-D, lanes 1-6). However, the patterns for the strains CBS 103.69 and IMI 138258 were not identical (Fig. 2A, C-D, lanes 6 and 7). Six of the eight Fujimori \& Okuda (NR) isolates also displayed very similar patterns (Fig. 2A-D, lanes 13-20), but despite their high ITS1 and 2 sequence homology with strains described as T. harzianum, these showed no similarity to the RAPD patterns of T. harzianum CBS 819.68 (Fig. 2A-D, lane 23). Two DNAs, one isolated from a single ascospore culture and the other from stroma tissue of a specimen deposited as H. aureoviridis (DAOM 172826), were similar to each other with minor differences in $(\mathrm{GTG})_{5}$ and M13 patterns (Fig. 2A-D, lanes 11-12). All remaining strains yielded unique patterns, regardless of the primer used.

\section{Morphological investigations}

Ascospore isolates and redescription of $\mathrm{T}$. aureoviride

Of the 20 cultures, 9 were from specimens identified as $H$. aureoviridis, of which only eight are from separate isolations: IMI 138258 is the same as CBS 103.69, and DAOM 172826 $A$ and $B$ are derived from a single specimen as was noted above. The ex-type culture of T. aureoviride (CBS 245.63) was derived from ascospores of SHD-M 2663, H. aureoviridis. All other strains were isolated directly from diverse substrata. The Hypocrea specimens from which six of these cultures were derived agreed well in morphology with the lectotype specimen of $H$. aureoviridis (K (M)!) and with the description of Rifai \& Webster (1966) for the species. The anamorphs formed in these cultures agreed well with Rifai \& Webster (1966). These six specimens and their cultures are taken to be 'true' $H$. aureoviridis, and the description given below is based on them.

Although some strains grew faster than others (most notably CBS 138.79), all grew slowly relative to other Trichoderma isolates, reaching only $40-75 \mathrm{~mm}$ diam after one wk on MEA and PDA at the optimum temperature of $20^{\circ}$. On average, colonies incubated in alternating light and darkness grew slightly slower than those incubated in darkness with only intermittent and infrequent exposure to light. After $64 \mathrm{~h}$ on PDA and SNA there was no growth at $30^{\circ}$ or $35^{\circ}$. On MEA at $20^{\circ}$ in darkness after 1 wk colonies were uniformly flat and velvety. Aerial mycelium comprised short hyphae that formed a uniform lawn over the colony; concentric rings were generally lacking except for IMI 355906 and IMI 311745, in which a centrally located ring of intense conidial production was observed. There was more dense production of aerial mycelium on PDA.

Within one week, cultures grown on MEA under a regimen of $12 \mathrm{~h}$ darkness $/ 12 \mathrm{~h}$ cool white fluorescent light produced more or less intense yellow pigment that was most easily seen in the colony reverse. No pigment was observed in cultures incubated in darkness with only intermittent and infrequent exposure to light. Needle-like, yellow crystals were observed in MEA cultures of IMI 355906 and IMI 311745; crystals were not observed in the ex-type strain (CBS 243.63) but yellowish, amorphous material was produced sporadically in MEA cultures of it.

Conidial production equally abundant on MEA and PDA, in either darkness or in light, but poor on CMD. Conidiophores (Figs 3-4, 7) 50-100 $\mu \mathrm{m}$ long, smooth, typically branched along the length in a verticillate fashion, or branching at or near the tip and then in a gliocladium-like fashion, arising from the surface of the agar or from aerial hyphae typically formed in a continuous and uniform lawn throughout the colony with no tendency to form pustules. Phialides divergent from the point of basal attachment to the conidiophore and irregularly or regularly disposed along the conidiophore, or forming a broad penicillus toward the tip, straight, tapering slightly from base to tip, 9-15 $\mu \mathrm{m}$ long, 2.5-3 $\mu \mathrm{m}$ wide in the middle, 2.5$3 \mathrm{~m}$ wide at the base; periclinal thickening visible at the tip, the collarette flared; the phialides persistent with age.

Conidia typically clavate (Fig. 5) to ellipsoidal or subglobose (Fig. 6) $(\mathrm{l} / \mathrm{w}=1.4-1.8)$ often with a truncate or slightly protuberant base, 3.5-5 $\times 2.5-3 \mu \mathrm{m}$, smooth; held in drops of clear, virtually colourless (extremely pale green when seen with the stereo microscope) watery liquid that, in mass, typically gave the colony a greyish green color (27B5). IMI 355906 and IMI 311745 differed from the other 4 strains in producing zonate colonies. The zonation in conidial production was especially marked on PDA cultures incubated in the light and was accompanied by the production of olive yellow to olive pigment in the colony (3D-F8).

\section{Teleomorphs}

With the exception of CBS 138.79, collected in The Netherlands, all the Hypocrea collections were made in the UK and the cultures were derived from ascospores. The strain CBS 628.77 was identified as $H$. aureoviridis, but was isolated from foodstuff and not ascospores.

The Canadian specimen (DAOM $172826 \mathrm{~A}$ and B), originally identified as $H$. aureoviridis, was superficially similar in gross morphology and in green ascospores, but differed from typical $H$. aureoviridis in having larger ascospores and in an anamorph that resembles T. strictipilis (Bissett 1991b). Additionally, the anamorph of DAOM 172826 was easily distinguished from T. aureoviride. DAOM 172826 did not cluster with any other strains and resembles $H$. aureoviridis $\mathrm{f}$. macrospora Doi (Doi 1972) both in anamorph and teleomorph. Original cultures of the form are no longer available.

\section{Conidial isolates}

Fourteen strains that had been identified as T. aureoviride were derived directly from diverse natural substrata. All were fast growing, covering a $9 \mathrm{~cm}$ diam Petri dish within $4 \mathrm{~d}$ at $25^{\circ}$ and all grew at $35^{\circ}$; all had conidia that were smaller than is typical for T. aureoviride. Most fell into ITS group B; their conidiophores and subglobose conidia were typical of $T$. harzianum (sensu Gams \& Meyer 1998; Figs 8-10). Several of these strains produced an intense yellow pigment on PDA and their hyphae were filled with amorphous yellow material. The single strain in ITS group C (IMI 091968) was typical of $T$. citrinoviride, a member of the H. schweinitzii complex (Samuels et al. 1998). 


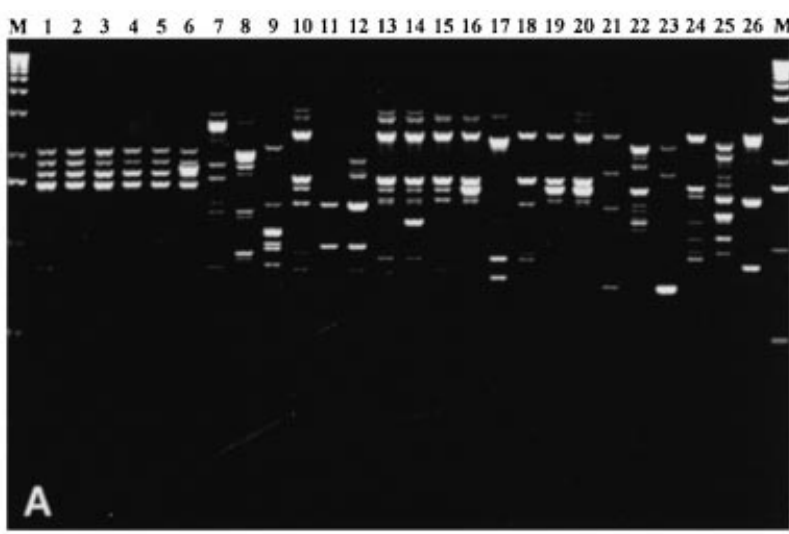

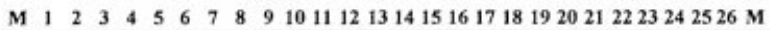

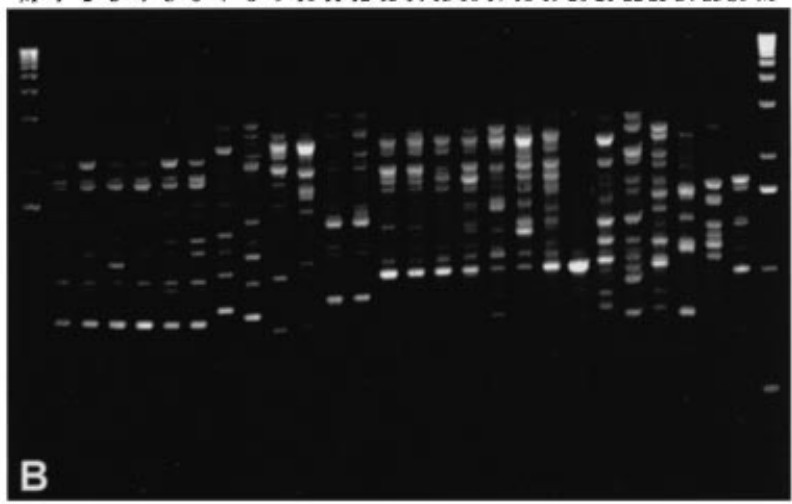

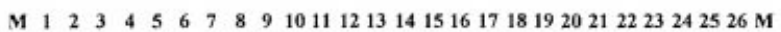
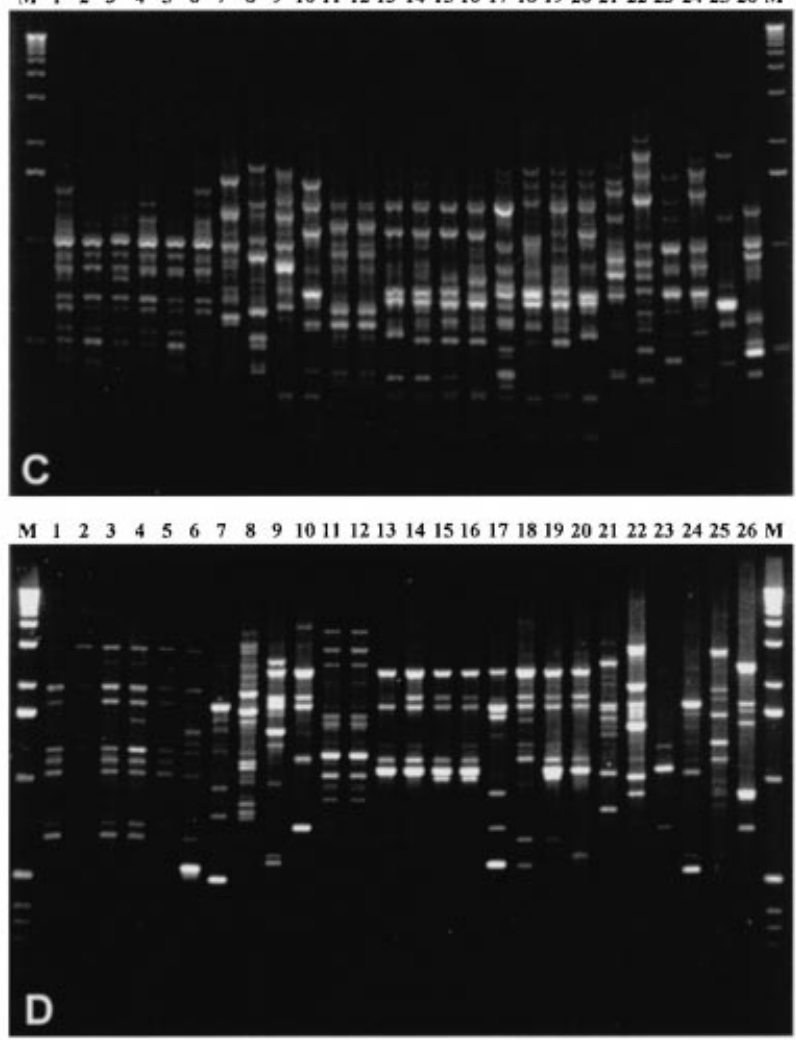

Fig. 2. Hypocrea aureoviridis/Trichoderma aureoviride PCR fingerprinting patterns of genomic DNA revealed by primers M13 (A), $(\mathrm{GTG})_{5}(\mathrm{~B}),(\mathrm{GACA})_{4}(\mathrm{C})$, and ROB (D). Lanes: $M, 1 \mathrm{~kb}$ ladder (Life Science Technologies). 1, T. aureoviride ex-type CBS 245.63. 2, H. aureoviridis CBS 138.79, 3, H. aureoviridis IMI 355906. 4, H. aureoviridis IMI 311745. 5, H. aureoviridis CBS 103.69. 6, H. aureoviridis IMI 138258. 7, H. aureoviridis CBS 628.77. 8, T. aureoviride

\section{DISCUSSION}

Rifai \& Webster (1966) redescribed and lectotypified Hypocrea aureoviridis, and were the first to link the species to a Trichoderma anamorph, later described as the T. aureoviride aggregate (Rifai 1969). This new Trichoderma name was based on ascospore isolations from a collection identified by Rifai \& Webster (1966) as $H$. aureoviridis (SHD-M 2663=CBS 245.63). There is no reason to doubt that Rifai \& Webster correctly identified $H$. aureoviridis and that T. aureoviride is $H$. aureoviridis. They provided a complete description and illustrations of stromata of $H$. aureoviridis. They characterized the species as very slow growing with few aerial hyphae, a watery white mycelium, yellow needle-like crystals and a dirty yellow to brownish reverse. With the exception of the crystals, which were lacking from most of the cultures that we studied, these characteristics were noted for the ex-type strain (CBS 245.63) and the six H. aureoviridis strains clustering with it. Yellow needle-like crystals were found in two of the more recent IMI cultures. Despite the characteristic slow growth rate that Rifai \& Webster documented for the species, which is unusual in Trichoderma and Hypocrea (compare growth rates for other species of Trichoderma and Hypocrea in Samuels et al. 1998, Lieckfeldt et al. 1998b, Seaby 1996, Samuels, pers. obs.), the species has been repeatedly misidentified. If the name of an organism is a key to communication about it, then - as has often happened in Trichoderma-communication about $T$. aureoviride has failed. Reports attributing activities and properties to $T$. aureoviride are erroneous, referring mainly to T. harzianum. In the present work we re-emphasize diagnostic characters of $T$. aureoviride to enable its correct identification while, at the same time, leading diagnosticians to other more likely names.

It is difficult to speculate as to why this species has been misidentified so frequently, but the production a diffusing yellow pigment in agar media may have been misleading. In addition to yellow crystals, Rifai (1969) attributed a diffusing brownish yellow pigment to $T$. aureoviride. Diffusing yellow pigment is found also in distantly related species of Hypocrea, including H. schweinitzii (T. citrinoviride) and other members of the H. schweinitzii complex (Samuels et al. 1998) as well as in some strains of T. harzianum (Trichoderma sect. Pachybasium; Seaby 1996, Samuels pers. obs.).

Trichoderma aureoviride is unusual in Hypocrea because of the tendency for its conidiophores to be finite in length, as opposed to typical Trichoderma's where well-defined conidiophores are not formed (Samuels, 1996). Further, its phialides tend to be disposed in a gliocladium- or verticillium-like fashion (Figs 4, 7) and taper uniformly from base to tip rather

IMI 091968. 9, T. aureoviride IMI 113135. 10, T. aureoviride IMI 112086. 11, H. aureoviridis DAOM 172826A. 12, H. aureoviridis DAOM 172826B. 13, T. harzianum NR 5546. 14, T. harzianum NR 5555. 15, T. harzianum NR 6883. 16, T. harzianum NR 6929. 17, T. harzianum NR 6931. 18, T. harzianum NR 6938. 19, T. harzianum NR 6940. 20, T. harzianum NR 6950. 21, T. aureoviride BBA 65638. 22, H. vinosa CBS 247.63. 23, T. harzianum CBS 819.68. 24, T. inhamatum CBS 273.78. 25, T. longibrachiatum ATCC 18648. 26, T. koningii ATCC 64262 . 

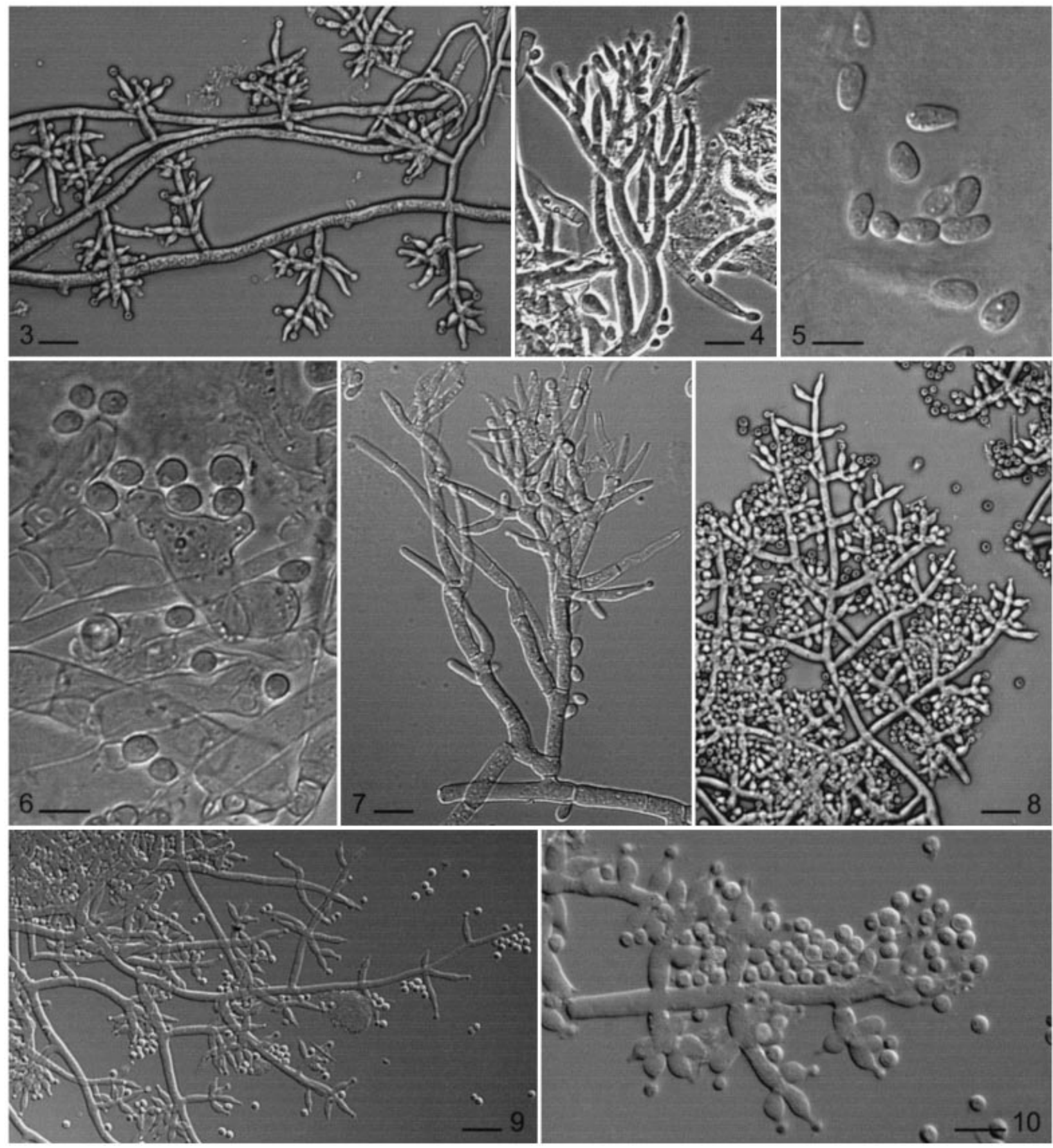

Figs 3-10. Hypocrea aureoviridis/Trichoderma aureoviride, conidiophores and conidia. Figs 1-5. CBS 245.63, the ex-type culture of T. aureoviride. Fig. 6. IMI 311745. Fig. 7. IMI 355906. Figs 8-10. T. harzianum misidentified as T. aureoviride. Fig. 8 NR 6938. Figs 9-10. NR 6931. Bars: Figs $3-4,7-9=10 \mu \mathrm{m}$; Figs $5-6,10=5 \mu \mathrm{m}$.

than being enlarged in the middle (compare Figs 4, 7 with Figs 8 , 10). Finally, while Trichoderma conidia are typically held in powdery masses, we know of only a few species that produce their conidia in watery heads, namely T. virens, H. gelatinosa, and H. lutea ('Gliocladium' viride). Trichoderma virens and $H$. aureoviridis are not obviously closely related (Fig. 1). Hypocrea lutea and H. gelatinosa are the subject of continuing study in our laboratory (P. Chaverri, unpubl.).

In the phylogenetic analysis the $H$. aureoviridis clade was very strongly supported. Although Rifai (1969) included the anamorph of $H$. vinosa in the morphological concept of $H$. aureoviridis, molecular characters do not support this place- ment. The anamorph of $H$. aureoviridis is easily distinguished from that of H. vinosa at the species level, but Kindermann et al. (1998) demonstrated that morphology in Trichoderma is not necessarily a good predictor of interspecies relationships and so it was reasonable for Rifai \& Webster to propose a relationship between $H$. vinosa and $H$. aureoviridis. Hypocrea vinosa was described in the last century from a specimen collected in New Zealand. We are only aware of one culture to have been derived from ascospores of a specimen identified as $H$. vinosa (CBS 247.63) and that clusters in a clade that includes $H$. rufa (Fig. I, as its anamorph T. viride). A second culture, isolated directly from soil in the USA and identified as 
H. vinosa, is T. harzianum. Our results confirm those of Bissett (1991b) and Gams \& Bissett (1998) in regarding $H$. aureoviridis/T. aureoviride as a phylogenetic species.

Although there was some genetic variation within the $T$. aureoviride clade, those branches were not well supported. The surprising deviation in ITS- 1 and 2 sequences and in RAPD patterns of the two cultures of the single $H$. aureoviridis strain CBS 103.69 and IMI 238258 is perhaps a result of the separate cultivation/storage history of the respective cultures in different culture collections over approximately 30 years. A contamination of one of the cultures can be excluded, because contamination should have resulted in a much more pronounced genetic difference; it is highly unlikely that the contaminant would have been another strain of $H$. aureoviridis. There was no evidence for multiple ITS types in $H$. aureoviridis cultures as repeated sequencing of new DNAs gave exactly the same unique sequence for each culture. There was some phenotypic variation within the clade, for example IMI 311745 has smaller conidia and a faster growth rate, but we cannot assess the taxonomic significance of these differences given the small number of specimens available.

In an updated key to Trichoderma, Gams \& Bissett (1998) maintained T. aureoviride in sect. Trichoderma, and described it on the basis of isolate CBS 283.79, which originated from the same location as strain CBS 138.79. The latter was included in the present study and shown to be a member of the clade containing the ex-type strain, CBS 245.63. However, our molecular data do not support the inclusion of T. aureoviride in sect. Trichoderma or in any other recognized section of the genus. In contrast, the strains described by Fujimori \& Okuda (1994) as T. aureoviride display physiological, morphological and molecular characters that correlate with those reported for T. harzianum. In fact, Okuda et al. (1982) and Fujimori \& Okuda (1994) mentioned the similarity of $T$. aureoviride to $T$. harzianum, and by the time they were obtained for this study some had been reidentified as T. harzianum (see Table 1).

Strain DAOM 172826, which according to Bissett (1991b) has affinity to $H$. aureoviridis and resembles $T$. atroviride, is similar to $H$. aureoviridis in phenotypic characters (stroma), but is otherwise not very much like T. atroviride. Molecular data place this strain basal to the former sect. Pachybasium (clade B in Kindermann et al. 1998). On the other hand, there is a short sequence motif in ITS-1 at bp 166-170 (AAAAA) in which DAOM 172826 is similar to that of the T. aureoviride ex-type group (AAGAA) and absent in all other Trichoderma and Hypocrea isolates investigated so far. According to our recent findings, we introduce a new group, 'E', for Hypocrea sp. DAOM 172826; this Hypocrea is possibly $H$. aureoviridis $f$. macrospora (Doi 1972), based on the description and illustrations of that taxon and our study of a paratype specimen (NY).

In summary, $H$. aureoviridis is a rare species seemingly restricted to northwestern Europe (The Netherlands and UK). It has been encountered only in isolations from ascospores. The data clearly demonstrate that many strains identified as $T$. aureoviride are actually members of sect. Pachybasium with a strong affinity to $T$. harzianum or T. inhamatum. High GCcontent of the ITSI and two sequences and the comparatively long sequence length place $H$. aureoviridis in an isolated position in Hypocrea. In contrast to the suggestion that it is closely related to H. rufa/T. viride (Bissett 1991a, Gams \& Bissett 1998), it is quite distinct from them and possibly represents a previously unrecognized group within Hypocrea. The anamorph, with conidia held in watery heads on gliocladium-like conidiophores, suggests relationship to $H$. gelatinosa and T. virens; ITS rDNA Sequences for H. gelatinosa are not yet available. Although our data (Fig. I) do not show a close relationship between $H$. aureoviridis and $T$. virens, we cannot rule out the possibility that such a relationship will be revealed with the study of additional taxa. Although the biogeographic study of Hypocrea is only in an early phase, we have not yet encountered a species that has such a restricted geographic distribution. The apparent restriction of $H$. aureoviridis to northwest Europe, despite extensive collecting in North America and Europe, and its slow growth rate in culture, suggest that it has adapted to particular growth factors found in its habitat. As a result of the geographic isolation there has been little gene flow and, thus, little genetic variation in the species.

On the basis of our results, we redefine $T$. aureoviride, limiting it to Trichoderma strains that are anamorphic $H$. aureoviridis and that have a very slow growth rate, effuse conidiation, and the ITS- 1 and 2 sequence type D.

\section{ACKNOWLEDGMENTS}

We thank Toru Okuda (Tanabe Seiyaku, Japan) and Mieko Yanagisawa (Nippon Roche, Japan) for providing strains. We are also grateful to B. Liebe, Y. Claußner, and J. Müller (Berlin) for technical assistance. The curators of CBS, DAOM, IMI, SHD, and NY are thanked for lending us specimens in their keeping. We thank Walter Gams (Centraalbureau voor Schimmelcultures), and Helen Rolf (formerly of CAB International, IMI), for providing us with cultures. This work was supported by grant EL 627/4 from the Deutsche Forschungsgemeinschaft (Bonn) to E.L., by a grant from the Fond der Chemischen Industrie (Frankfurt/M.) to T.B. (Humboldt-Universität Berlin), and one from the Austrian Science Foundation (P12748-MOB) to C.P.K. National Science Foundation Grant 97-12308 to the Pennsylvania State University (PEET grant) provided partial support for G.J.S.

\section{REFERENCES}

Bissett, J. (1984) A revision of the genus Trichoderma. I. Section Longibrachiatum sect. nov. Canadian Journal of Botany 62 : 924-931.

Bissett, J. (1991a) A revision of the genus Trichoderma. II. Infrageneric classification. Canadian Journal of Botany 69: 2357-2372.

Bissett, J. (1991b) Trichoderma atroviride. Canadian Journal of Botany 70: 639-641.

Bruce, A., Srinivasan, U., Staines, H. J. \& Highley, T. L. (1995) Chitinase and laminarinase production in liquid culture by Trichoderma spp. and their role in biocontrol of wood decay fungi. International Biodeterioration \& Biodegradation 35 : 337-353.

Bruce, A., Knudzewicz, A. \& Wheatley, R. (1996) Influence of culture age on the volatile organic compounds produced by Trichoderma aureoviride and associated inhibitory effects on selected woody decay fungi. Materiel und Organismen 30: 79-90.

Calvet, C., Pera, J. \& Barea, J. M. (1993) Growth response of marigold (Tagetes erecta L.) to inoculation with Glomus mossae, Trichoderma aureoviride and Pythium ultimum in a peat-perlite mixture. Plant and Soil 148: 1-6.

Camprubi, A., Calvet, C. \& Estaun, V. (1995) Growth enhancement of Citrus reshni after inoculation with Glomus mossae and Trichoderma aureoviride and associated effects on microbial populations and enzyme activity in potting mixes. Plant and Soil 173: 233-238.

Cutler, H. G., Cutler, S. J., Ross, S. A., Sayed, K. E., Dugan, F. M., Bartlett, M. G., Hill, A. A., Hill, R. A. \& Parker, S. R. (1999) Koninginin G, a new 
metabolite from Trichoderma aureoviride. Journal of Natural Products 62: 137-139.

Doi, Y. (1972) Revision of the Hypocreales with cultural observations. IV. The genus Hypocrea and its allies in Japan (2) Enumeration of the species. Bulletin of the National Science Museum 15 : 649-751.

Fujimori, F. \& Okuda, T. (1994) Application of the random amplified polymorphic DNA using the polymerase chain reaction for efficient elimination of duplicate strains in microbial screening. I. Fungi. Journal of Antibiotics 47: 173-182.

Gams, W. \& Bissett, J. (1998) Morphology and identification of Trichoderma. In Trichoderma and Gliocladium (C. P. Kubicek \& G. E. Harman, eds): 3-34. Taylor \& Francis, London.

Gams, W. \& Meyer, W. (1998) What exactly is Trichoderma harzianum? Mycologia 90: 904-914.

Kindermann, J., El-Ayouti, Y., Samuels, G. J. \& Kubicek, C. P. (1998) Phylogeny of the genus Trichoderma based on sequence analysis of the internal transcribed spacer region 1 of the rDNA cluster. Fungal Genetetics and Biology 24 : 298-309.

Kornerup, A. \& Wanscher, J. H. (1978) Methuen Handbook of Colour. Methuen, London.

Kubicek, C. P. (1982) $\beta$-Glucosidase excretion by T. pseudokoningii, correlation with cell wall bound $\beta$-1,3-glucanase activities. Archiv für Microbiologie 132: 349-354.

Kuhls, K., Lieckfeldt, E. \& Börner, T. (1995) PCR-fingerprinting used for comparison of ex type strains of Trichoderma species deposited in different culture collections. Microbiological Research 150: 363-371.

Kuhls, K., Lieckfeldt, E., Samuels, G. J., Kovacs, W., Meyer, W., Petrini, O., Gams, W., Börner, T. \& Kubicek, C. P. (1996) Molecular evidence that the asexual industrial fungus Trichoderma reesei is a clonal derivative of the ascomycete Hypocrea jecorina. Proceedings of the National Academy of Sciences, USA 93: 7755-7760.

Kuhls, K., Lieckfeldt, E., Samuels, G. J., Meyer, W., Kubicek, C. P. \& Börner, T. (1997) Revision of Trichoderma sect. Longibrachiatum including related teleomorphs based on analysis of ribosomal DNA internal transcribed spacer sequences. Mycologia 89: 442-460.

Lieckfeldt, E., Kuhls, K. \& Muthumeenakshi, S. (1998a) Molecular taxonomy of Trichoderma and Gliocladium and their teleomorphs. In Trichoderma and Gliocladium (C. P. Kubicek \& G. E. Harman, eds): 35-56. Taylor \& Francis, London.
Lieckfeldt, E., Samuels, G. J., Börner, T. \& Gams, W. (1998b) Trichoderma koningii, neotypification and Hypocrea teleomorph. Canadian Journal of Botany 76: 1507-1522.

Lieckfeldt, E., Samuels, G. J., Nirenberg, H. I. \& Petrini, O. (1999) A morphological and molecular perspective of Trichoderma viride, is it one or two species? Applied and Environmental Microbiology 65 : 2418-2428.

Nirenberg, H. I. (1976) Untersuchungen über die morphologische und biologische Differenzierung in der Fusarium-Sektion Liseola. Mitteilungen aus der Biologischen Bundesanstalt für Land-und Forstwirtschaft, Berlin-Dahlem 169: 1-117.

Okuda, T., Fujiwara, A. \& Fujiwara, M. (1982) Correlation between species of Trichoderma and production patterns of isonitrile antibiotics. Agricultural and Biological Chemistry 46: 1811-1822.

Phillips, W. \& Plowright, C. B. (1880) New and rare British fungi. Grevillea 8 : 97-109.

Rifai, M. A. \& Webster, J. (1966) Culture studies on Hypocrea and Trichoderma. Transactions of the British Mycological Society 49: 289-296.

Rifai, M. A. (1969) A revision of the genus Trichoderma. Mycological Papers 116: $1-56$.

Samuels, G. J. (1996) Trichoderma: a review of biology and systematics of the genus. Mycological Research 100: 923-935.

Samuels, G.J, Petrini, O., Kuhls, K., Lieckfeldt, E. \& Kubicek, C. P. (1998) The Hypocrea schweinitzii complex and Trichoderma sect. Longibrachiatum. Studies in Mycology 41 : 1-55.

Samuels, G. J., Lieckfeldt, E. \& Nirenberg, H. I. (1999) Trichoderma asperellum, a new species with warted conidia, and redescription of T. viride. Sydowia 51: 7I-88.

Seaby, D. A. (1996) Differentiation of Trichoderma taxa associated with mushroom production. Plant Pathology 45 : 905-912.

Swofford, D. L. (1998) PAUP* Phylogenetic Analysis Using Parsimony (* and other methods). Version 4. Sinauer Associates, Sunderland, MA.

Vilgalys, R. \& Hester, M. (1990) Rapid genetic identification and mapping of enzymatically amplified ribosomal DNA from several Cryptococcus species. Journal of Bacteriology 172: 4238-4246.

Webster, J. (1964) Culture studies on Hypocrea and Trichoderma I. Comparison of perfect and imperfect states of Hypocrea gelatinosa, H. rufa and Hypocrea sp. I. Transactions of the British Mycological Society 47: 75-96.

Corresponding Editor: D. L. Hawksworth 